of value as an aid to diagnosis, and for this reason alone its performance as a routine measure in the course of the examination of blind persons is justified.

Specific Fevers.

The specific fevers were a comparatively unimportant cause of blindness, only 39 cases ( 1.02 per cent.) being regarded as resulting from infectious disease. Measles was responsible for by far the greatest number, accounting for 28 cases; smallpox accounted for 6 cases, scarlet fever for 4 cases, while the cause in the remaining case was unspecified. As would be expected, the onset of the ocular condition occurred before the age of 15 in all but two instances. Corneal opacity was responsible for blindness in 28 cases, uveitis (9 cases) being the only other defect of importance. Meningitis.

Thirty-nine cases were regarded as blind from meningitis. The onset of blindness in more than two-thirds of these occurred before the age of 15 years. It is of interest to observe that only $34 \cdot 2$ per cent. $\pm 7 \cdot 6$ were males, a figure which while not statistically significant suggests a higher incidence of this condition in the female sex. The defects found were-

\begin{tabular}{|c|c|}
\hline 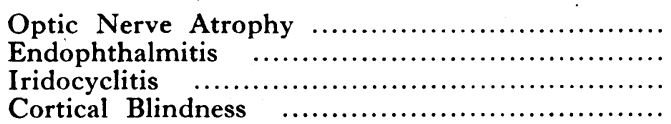 & $\begin{array}{r}32 \text { cases } \\
3 \text { cases } \\
2 \text { cases } \\
2 \text { cases }\end{array}$ \\
\hline
\end{tabular}

Phlyctenular Disease and Tuberculosis.

There were 84 cases ( 2.61 per cent.) blind as a result of phlyctenular disease, in 82 of which both eyes were similarly affected. The onset of the diseases in the vast hajority took place under 30 years, the average age of onset being 10 years. The occurrence of blindness, on the other hand, was insidious, the mean age, however, being 3:) years. The defect in all cases was corneal ulceration.

It is now considered that phlyctenular disease is tuberculoallergic in nature, but it is improbable that all the cases included under this heading were of this category. It is worthy of mention that 20 cases $(0.6$ per cent.) in this analysis have been placed in a separate group as due to tuberculosis.

( To be continued)

\title{
ANNOTATION
}

\section{On Holiday Duty}

Our heading has in this instance no ecclesiastical or scholastic significance. Every one is entitled to an annual holiday if he can get it and we most of us manage to do so and to ensure that our 
work is maintained during our absence. It used not to be so. In Brodie's life it is stated that for many years he took no annual holiday, but contented himself with living in a cottage in Hampstead during the summer months. Sir Anderson Critchett, we believe, after the death of his father, was so busy that he was unable to take a proper holiday for some years. The holiday duty devolves upon our junior: in Hospital work things run smoothly nearly always. Perhaps one or two of the older patients who have attended for years don't quite appreciate the attentions of a youngster instead of the elderly or ageing practitioner to whom they are accustomed. In private, things do not always go so harmoniously. We have known suspicious looking old ladies who have been quick to notice any departure from the attentions to which they have been accustomed. "You seem very young, I am surprised that $\mathrm{Mr}$. should have entrusted you with his patients" is. the sort of announcement we have encountered on some occasions.

Sir Anderson Critchett used to tell a good story of Mr. John Couper, who always took $\mathrm{Mr}$. George Critchett's holiday work. A very old lady called to see $\mathrm{Mr}$. Critchett and it was explained to her that he was away and that Mr. Couper would see her. She was so deaf that she didn't comprehend what was said and on leaving the consulting room congratulated the embarrassed $\mathrm{Mr}$. Couper, for having achieved a world-wide reputation at so early an age. In connexion with holiday duty we always like to remember the story of a wealthy vicar who was accustomed to take long holidays. On his return from one of these he noticed a woman with a baby in arms and asked, has that child been baptized?" Well sir, said the woman, I wouldn't like tojsay much as to that, but your young man came and did what he could." The same might with perfect justice be said to one of us by an old patient who has been dissatisfied with the attentions of our juniors.

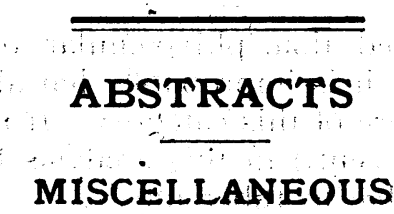

(1) de Rooy, A. J. P. M: (Amsterdam).-The relationship between retinal venous pressure and intracranial pressure. (Le rapport entre la tension veineuse rétinienne et la pression intracranienne). Ophthalmologica, Vol. XCIX, p. 484, 1940.

(1) Opinions concerning the relation between retinal venous and intracranial pressure differ, Bailliart amongst others holding there is no direct relationship, de Rooy gives the results of the 